\title{
Is the Volatility of the Market Price of Risk due to Intermittent Portfolio Re-balancing?*
}

\author{
YiLi Chien \\ Purdue University
}

\author{
Harold Cole \\ University of Pennsylvania
}

May 14, 2010

\author{
Hanno Lustig \\ UCLA Anderson
}

\begin{abstract}
Our paper examines whether the well-documented failure of unsophisticated investors to rebalance their portfolios can help to explain the enormous counter-cyclical volatility of aggregate risk compensation in financial markets. To answer this question, we set up a model in which CRRA-utility investors have heterogeneous trading technologies. In our model, a large mass of investors do not re-balance their portfolio shares in response to aggregate shocks, while a smaller mass of active investors adjust their portfolio each period to respond to changes in the investment opportunity set. We find that these intermittent re-balancers amplify the effect of aggregate shocks on the time variation in risk premia by a factor of three by forcing active traders to sell more shares in good times and buy more shares in bad times.
\end{abstract}

*We would like to thank Fernando Alvarez, Andrew Ang, Michael Brennan, Markus Brunnermeier, Bruce Carlin, Hui Chen, Bhagwan Chowdry, Bernard Dumas, Martin Lettau, Leonid Kogan, Stefan Nagel, Stavros Panageas, Monika Piazzesi and Martin Schneider, as well as the participants of SITE's 2009 Asset Pricing session and the 1st annual workshop at the Zurich Center for Computational Economics, the NBER EFG meetings in San Francisco, the ES sessions at the ASSA meetings in Atlanta and seminars at Columbia GSB, UCLA Anderson and MIT Sloan, for helpful comments. 


\section{Introduction}

One of the largest challenges for standard dynamic asset pricing models is to explain the enormous countercylical variation in the risk-return trade-off in asset markets. The standard explanations rely on countercyclical risk aversion and heteroscedasticity in aggregate consumption growth, but these explanations either do not have a strong micro foundation or they fall short quantitatively. Our paper establishes that the participation in equity markets of non-Mertonian investors who fail to continuously rebalance and who do not respond to changes in the investment opportunity set should be considered as an additional plausible explanation. Furthermore, we find that increased participation of non-Mertonian investors may actually lead to more volatility in risk premia by increasing the supply of slow-moving capital in financial markets.

There is a large group of households that invest in equities but only change their portfolio shares infrequently, even after large common shocks to asset returns. Ameriks and Zeldes (2004) find that over a period of 10 years $44 \%$ of households in a TIAA-CREF panel made no changes to either flow or asset allocations, while $17 \%$ of households made only a single change. Calvet, Campbell, and Sodini (2009), in a comprehensive data set of Swedish households, found a weak response of portfolio shares to common variation in returns: between 1999 and 2002, the equal-weighted share of household financial wealth invested in risky assets drops from $57 \%$ to $45 \%$ in 2002 , which is indicative of very weak re-balancing by the average Swedish household during the bear market. Finally, after examining two decades of panel data on US household asset allocation from the PSID and CEX surveys, Brunnermeier and Nagel (2008) conclude that inertia is the main driver of asset allocation in US household portfolios, while changes in wealth only play a minor role.

Without a specific model in mind, it is hard to know what effect, if any, intermittent re-balancing would have on equilibrium asset prices. In an equilibrium where all households are equally exposed to aggregate shocks, there is no need for any single household to re-balance his or her portfolio in response to an aggregate shock. This is clearest in a representative agent economy. However, in an environment in which households have heterogeneous exposures to aggregate shocks, the frequency of re-balancing may have important aggregate effects through its impact on the distribution of 
asset holdings.

We conjecture that infrequent re-balancing on the part of non-Mertonian investors may contribute to countercylical volatility in risk prices because intermittent rebalancers mimic the portfolio behavior of households with countercyclical risk aversion. When the economy is affected by an adverse aggregate shock and the price of equity declines as a result, non-Mertonian investors who re-balance end up buying equities to keep their portfolio shares constant, while intermittent rebalancers do not. Hence, in the latter case, more aggregate risk is concentrated among the smaller pool of Mertonian investors whenever the economy is affected by a negative aggregate shock.

To check the validity of this conjecture, we set up a standard incomplete markets model in which investors are subject to idiosyncratic and aggregate risk. The investors have heterogeneous trading technologies; a large mass of households are non-Mertonian investors who do not change their portfolio in response to changes in the investment opportunity set, but a smaller mass of active or Mertonian investors do. We consider two types of non-Mertonian investors: those that re-balance their portfolio each period to keep their portfolio shares constant, and those that rebalance intermittently. We assume that intermittent rebalancers reinvest the dividends in equities in non-rebalancing periods (see e.g. Duffie and Sun (1990)).

We find that the volatility of the price of aggregate risk is three times higher in the economy with intermittent rebalancers than in the economy with continuously re-balancing non-Mertonian investors. While the individual welfare loss associated with intermittent rebalancing is small relative to continuous rebalancing, and hence small costs would suffice to explain this behavior, the aggregate effects of non-rebalancing are large.

The automatic reinvestment assumption is critical for our results. ${ }^{1}$ If intermittent rebalancers do not reinvest the dividends, the amplification of the volatility in risk prices delivered by intermittent rebalancing is much smaller. To see why, consider the case in which the dividend yield is constant. Then the average investor can simply consume the dividends, and there is no need for trade in equity shares between Mertonian and non-Mertonian investors. However, if the intermittent rebalancers who are not rebalancing in that period simply reinvest the dividends, then they

\footnotetext{
${ }^{1}$ We thank Fernando Alvarez for drawing our attention to this.
} 
buy more shares than usual from the active investors after good shocks and they buy fewer shares than usual after bad shocks. That is the crux of our mechanism: it creates more exposure for active investors after bad shocks and less exposure after good shocks.

The heterogeneity in trading technologies allows us to generate substantial volatility in the risk premiums. We rely on two additional frictions to match the average risk-free rate and the average risk premium: (i) incomplete markets with respect to the idiosyncratic labor income risk and (ii) limited participation. The first friction produces reasonable risk-free rate implications in a growing economy. The second friction, limited participation, combined with the non-Mertonian trading technology of some market participants, produces a high average equity premium by concentrating aggregate risk, as in Chien, Cole, and Lustig (2010), but they only consider continuously rebalancing non-Mertonian investors. Our paper introduces intermittent rebalancers and shows that these traders increase the volatility of risk premia.

We use our model as a laboratory for exploring the effects of changes in the composition of the capital supply in financial markets. First, we show that increased participation by nonMertonian investors, i.e., an increase in the supply of slow-moving capital, decreases the average equity premium somewhat but substantially increases its volatility. Second, we find that financial innovation in the form of increased scope for hedging against idiosyncratic risk strengthens the amplification effect because of a third friction in the model: solvency constraints. When Mertonian investors can hedge against idiosyncratic risk, they have no precautionary motive to save and they run into frequently binding solvency constraints (see Alvarez and Jermann (2001) and Chien and Lustig (2010)). This strengthens our amplification mechanism: when fast-moving capital runs into binding solvency constraints, this amplifies the volatility-inducing effect of slow-moving capital.

From the perspective of existing Dynamic Asset Pricing Models (DAPM's), there is a puzzling amount of variation in the risk-return trade-off in financial markets. In standard asset pricing models, the price of aggregate risk is constant (see, e.g., the Capital Asset Pricing Model of Sharpe (1964) and Lintner (1965)) or approximately constant (see, e.g., Mehra and Prescott (1985)'s calibration of the Consumption-CAPM). ${ }^{2}$

\footnotetext{
${ }^{2}$ Recently, Campbell and Cochrane (1999) and Barberis, Huang, and Santos (2001), among others, have shown
} 
Habit formation preferences can help match the counter-cyclicality of risk premia in the data (Constantinides (1990), Campbell and Cochrane (1999)), as well as other features of the joint distribution of asset returns and macro-economic outcomes over the business cycle (see Jermann (1998), Boldrin, Christiano, and Fisher (2001)). However, it is not clear whether households actually have preferences defined over the difference between a habit and actual consumption. In fact, a key prediction of these preferences is that the household's risk aversion, and hence their allocation to risky assets, varies with wealth. According to Brunnermeier and Nagel (2008), there is little evidence of this in the data.

Moreover, these models do not seem to produce enough cyclical variation in Sharpe ratios to match the data. Lettau and Ludvigson (2001) measure the time-variation in the Sharpe ratio on equities in the data. This time variation is driven by variation in the conditional mean of returns (i.e. the predictability of returns) as well the variation in the conditional volatility of stock returns. In the data, these two objects are negatively correlated, according to Lettau and Ludvigson (2001), and this gives rise to a considerable amount of variation in the conditional Sharpe ratio: the annual standard deviation of the estimated Sharpe ratio is on the order of $50 \%$ per annum.

How close can existing DAPM's get to this number? An annual calibration of the Campbell and Cochrane (1999) external habit model with large variation in the investor's risk aversion produces a volatility of $21 \%$. The version of our model with the same i.i.d. aggregate consumption growth shocks and constant relative risk aversion investors (CRAA coefficient is five) delivers $15 \%$. The volatility produced by our model increases to $25 \%$ if we use the Mehra and Prescott (1985) calibration of aggregate consumption growth, which builds in some negative autocorrelation in aggregate consumption growth. Finally, our model delivers 34\% if Mertonian investors can hedge against idiosyncratic risk. Our model cannot completely close the gap with the data, at least not with this CRRA coefficient.

Other channels for time-variation in risk premia that have been explored in the literature include differences in risk aversion (Chan and Kogan (2002), Gomes and Michaelides (2008)), differences

that standard representative agent models with different, non-standard preferences can rationalize counter-cyclical variation in Sharpe ratios. 
in exposure to nontradeable risk (Garleanu and Panageas (2007)), participation constraints (Saito (1996), Basak and Cuoco (1998), Guvenen (2009)), differences in beliefs (Detemple and Murthy (1997)) and differences in information (Schneider, Hatchondo, and Krusell (2005)). Our paper imposes temporary participation constraints on the intermittent rebalancers instead of permanent ones, and it explores heterogeneity in trading technologies instead of heterogeneity in preferences.

Finally, there is a large literature on infrequent consumption adjustment starting with Grossman and Laroque (1990)'s analysis of durable consumption in a representative agent setting (see Alvarez, Guiso, and Lippi (2010) for a recent contribution to this literature). Lynch (1996) specifically focuses on the aggregate effects of infrequent consumption adjustment by heterogeneous consumers to explain the equity premium puzzle. Lynch (1996)'s model matches the low volatility of aggregate consumption and the low empirical correlation of market returns with aggregate consumption changes. Gabaix and Laibson (2002) extend this analysis to a tractable continuous-time setup that allows for closed-form solutions. Reis (2006) adopts a rational inattention approach to rationalize this type of behavior. As in Lynch (1996), Gabaix and Laibson (2002) and Duffie (2010), we assume that investors fix their periods of inattention rather than solving for the optimal inattention period. In our approach, the intermittent rebalancers choose an intertemporal consumption path to satisfy the Euler equation in each period, including non-rebalancing periods, but, in between rebalancing times, their savings decisions can only affect their holdings of the risk-free assets. Only in rebalancing periods can they actually change their equity holdings. Furthermore, our focus is exclusively on the volatility of equity risk premia. ${ }^{3}$

The outline of the paper is as follows. Section 2 describes the counter-cyclical variation in the Sharpe ratio in the data. Section 3 describes the environment and the trading technologies. Section 4 discusses the calibration of the model. Section 5 shows the results for the benchmark model with Mertonian investors who cannot hedge against idiosyncratic risk. Section 6 looks at asset prices when Mertonian investors can hedge against idiosyncratic risk. Finally, section 7 concludes.

\footnotetext{
${ }^{3}$ Duffie (2010) provides an overview of this literature in his 2010 AFA presidential address on slow-moving capital.
} 


\section{Counter-cyclical and volatile Sharpe ratios}

Lettau and Ludvigson (2001) measure the conditional Sharpe ratio on U.S. equities by forecasting stock market returns and realized volatility (of stock returns) using different predictors, and they obtain highly countercyclical and volatile Sharpe ratios. To get a clear sense of the link with business cycles, we consider a simple exercise. In expansions (recessions), the investor buys the stock market index in the $n$-th quarter after the NBER trough (peak) and sells after 4 quarters. The NBER defines recessions as periods that stretch from the peak to the trough. Strictly speaking, this is not an implementable investment strategy, because NBER peaks and troughs are only announced with a delay. ${ }^{4}$ Nonetheless, the average returns on this investment strategy provide a clear indication of the cyclical behavior of the expected returns conditional on the aggregate state being expansion (recessions).

Figure 1 plots the Sharpe ratio on this investment strategy in the U.S. stock market, conditioning on the quarter of the NBER recession/expansion. We plot the (sample) Sharpe ratios obtained in both subsamples. This Sharpe ratio, which conditions only on the stage in the NBER business

cycle, clearly increases in recessions (after the peak) and decreases in expansions (after the trough). The smoothed version of the conditional Sharpe ratio peaks three quarters into the recession at about 0.60 , and it reaches its low three quarters after the trough at about 0.1 . Our objective is to show that a reasonable model with constant relative risk aversion investors can mimic this counter-cyclical variation in Sharpe ratios.

[Figure 1 about here.]

\section{Model}

We consider an endowment economy in which households sequentially trade assets and consume. All households are ex ante identical, except for the restrictions they face on the menu of assets that they can trade. These restrictions are imposed exogenously. We refer to the set of restrictions that

\footnotetext{
${ }^{4}$ However, there is recent evidence that agents realize a recession has started about 1 quarter after the peak (see Doms and Morin (2004)).
} 
a household faces as a household trading technology. The goal of these restrictions is to capture the observed portfolio behavior of most households.

We will refer to households as being non-Mertonian traders if they take their portfolio composition as given and simply choose how much to save or dissave in each period. Other households optimally change their portfolio in response to changes in the investment opportunity set. We refer to these traders as Mertonian traders since they actively manage the composition of their portfolio each period. To solve for the equilibrium allocations and prices, we extend the method developed by Chien, Cole, and Lustig (2010) to allow for non-Mertonian traders who only intermittently adjust their portfolio. In this section, we describe the environment and we describe the household problem for each of the different asset trading technologies. We also define an equilibrium for this economy.

\subsection{Environment}

There is a unit measure of households who are subject to both aggregate and idiosyncratic income shocks. Households are ex ante identical, except for the trading technology they are endowed with. Ex post, these households differ in terms of their idiosyncratic income shock realizations. All of the households face the same stochastic process for idiosyncratic income shocks, and all households start with the same present value of tradeable wealth.

In the model time is discrete, infinite, and indexed by $t=0,1,2, \ldots$ The first period, $t=0$, is a planning period in which financial contracting takes place. We use $z_{t} \in Z$ to denote the aggregate shock in period $t$ and $\eta_{t} \in N$ to denote the idiosyncratic shock in period $t$. $z^{t}$ denotes the history of aggregate shocks, and similarly, $\eta^{t}$ denotes the history of idiosyncratic shocks for a household. The idiosyncratic events $\eta$ are i.i.d. across households with mean zero. We use $\pi\left(z^{t}, \eta^{t}\right)$ to denote the unconditional probability of state $\left(z^{t}, \eta^{t}\right)$ being realized. The events are first-order Markov, and we assume that

$$
\pi\left(z^{t+1}, \eta^{t+1} \mid z^{t}, \eta^{t}\right)=\pi\left(z_{t+1} \mid z_{t}\right) \pi\left(\eta_{t+1} \mid z_{t+1}, \eta_{t}\right)
$$

Since we can appeal to a law of large number, $\pi\left(z^{t}, \eta^{t}\right) / \pi\left(z^{t}\right)$ also denotes the fraction of agents in 
state $z^{t}$ that have drawn a history $\eta^{t}$. We use $\pi\left(\eta^{t} \mid z^{t}\right)$ to denote that fraction. We introduce some additional notation: $z^{t+1} \succ z^{t}$ or $y^{t+1} \succ y^{t}$ means that the left hand side node is a successor node to the right hand side node. We denote by $\left\{z^{\tau} \succ z^{t}\right\}$ the set of successor aggregate histories for $z^{t}$ including those many periods in the future; ditto for $\left\{\eta^{\tau} \succ \eta^{t}\right\}$. When we use $\succeq$, we include the current nodes $z^{t}$ or $\eta^{t}$ in the set.

There is a single non-durable goods available for consumption in each period, and its aggregate supply is given by $Y_{t}\left(z^{t}\right)$, which evolves according to

$$
Y_{t}\left(z^{t}\right)=\exp \left\{z_{t}\right\} Y\left(z^{t-1}\right)
$$

with $Y\left(z^{0}\right)=1$. This endowment goods comes in two forms. The first part is non-diversifiable income that is subject to idiosyncratic risk and it is given by $\gamma Y\left(z^{t}\right) \eta_{t}$; hence $\gamma$ is the share of income that is non-diversifiable. The second part is diversifiable income, which is not subject to the idiosyncratic shock, and is given by $(1-\gamma) Y_{t}\left(z^{t}\right)$.

All households are infinitely lived and rank stochastic consumption streams according to the following criterion

$$
U(\{c\})=\sum_{t \geq 1,\left(z^{t}, \eta^{t}\right)}^{\infty} \beta^{t} \pi\left(z^{t}, \eta^{t}\right) \frac{c_{t}\left(z^{t}, \eta^{t}\right)^{1-\alpha}}{1-\alpha},
$$

where $\alpha>0$ denotes the coefficient of relative risk aversion, and $c_{t}\left(z^{t}, \eta^{t}\right)$ denotes the household's consumption in state $\left(z^{t}, \eta^{t}\right)$.

\subsection{Assets Traded}

Households trade assets in securities markets that re-open every period. These assets are claims on diversifiable income, and the set of traded assets, depending on the trading technology, can

include one-period Arrow securities as well as debt and equity claims. Households cannot directly trade claims to aggregate non-diversifiable income (labor income). 
Debt and Equity We follow Abel (1999) in defining equity as a leveraged claim to aggregate diversifiable income $\left((1-\gamma) Y_{t}\left(z^{t}\right)\right)$. We use $V_{t}[\{X\}]\left(z^{t}\right)$ to denote the no-arbitrage price of a claim to a payoff stream $\{X\}$ in period $t$ with history $z^{t}$, and we use $R_{t+k, t}[\{X\}]\left(z^{t+k}\right)$ to denote the gross return between $t$ and $t+k . R_{t+1, t}[\{1\}]\left(z^{t}\right)$ denotes the one-period risk-free rate. To construct the debt and the equity claim, we assume that aggregate diversifiable income in each period is split into a debt component (aggregate interest payments net of new issuance) and an equity component (aggregate dividend payments net of new equity issuance denoted $D_{t}\left(z^{t}\right)$ ). For simplicity, the bonds are taken to be one-period risk-free bonds. Since we assume a constant leverage ratio $\psi$, the supply of one-period non-contingent bonds $B_{t}^{s}\left(z^{t}\right)$ in each period needs to adjust such that:

$$
B_{t}^{s}\left(z^{t}\right)=\psi\left[(1-\gamma) V_{t}[\{Y\}]\left(z^{t}\right)-B_{t}^{s}\left(z^{t}\right)\right]
$$

where $V[\{Y\}]\left(z^{t}\right)$ denotes the value of a claim to aggregate income in node $z^{t}$. The payout to bond holders is given by $R_{t, t-1}[1]\left(z^{t-1}\right) B_{t-1}^{s}\left(z^{t-1}\right)-B_{t}^{s}\left(z^{t}\right)$, and the payments to shareholders, $D_{t}\left(z^{t}\right)$, are then determined residually as:

$$
D_{t}\left(z^{t}\right)=(1-\gamma) Y_{t}\left(z^{t}\right)-R_{t, t-1}\left(z^{t-1}\right)[1] B_{t-1}^{s}\left(z^{t-1}\right)+B_{t}^{s}\left(z^{t}\right) .
$$

A trader who invests a fraction $\psi /(1+\psi)$ in bonds and the rest in debt is holding the market portfolio. We can denote the value of the dividend claim as $V_{t}[\{D\}]\left(z^{t}\right) . R_{t, t-1}[\{D\}]\left(z^{t}\right)$ denotes the gross return on the dividend claim between $t-1$ and $t$.

We denote the price of a unit claim to the final good in aggregate state $z^{t+1}$ acquired in aggregate state $z^{t}$ by $Q_{t}\left(z_{t+1}, z^{t}\right)$. If there is a group of agents who trade claims with payoffs that are contingent on their idiosyncratic shocks, the absence of arbitrage would imply that the price $Q_{t}\left(\eta_{t+1}, z_{t+1} ; \eta^{t}, z^{t}\right)$ of a claim to output in state $\left(z^{t+1}, \eta^{t+1}\right)$ acquired in state $\left(z^{t}, \eta^{t}\right)$ would be equal to $\pi\left(\eta^{t+1} \mid z^{t+1}, \eta^{t}\right) Q_{t}\left(z_{t+1}, z^{t}\right)$. We assume that there is a group of these agents, even if it is measure zero.

We consider a household entering the period with net financial wealth $\hat{a}_{t}\left(z^{t}, \eta^{t}\right)$. This household 
buys securities in financial markets (state contingent bonds $a_{t}\left(z^{t+1}, \eta^{t+1}\right)$, non-contingent bonds $b_{t}\left(z^{t}, \eta^{t}\right)$, and equity shares $\left.s_{t}^{D}\left(z^{t}, \eta^{t}\right)\right)$ and consumption $c_{t}\left(z^{t}, \eta^{t}\right)$ in the good markets subject to this one-period budget constraint:

$$
\begin{aligned}
& \sum_{z^{t+1} \succ z^{t}, \eta^{t+1} \succ \eta^{t}} Q_{t}\left(\eta_{t+1}, z_{t+1} ; \eta^{t}, z^{t}\right) a_{t}\left(z^{t+1}, \eta^{t+1}\right)+s_{t}^{D}\left(z^{t}, \eta^{t}\right) V_{t}[\{D\}]\left(z^{t}\right) \\
& +b_{t}\left(z^{t}, \eta^{t}\right)+c_{t}\left(z^{t}, \eta^{t}\right) \leq \hat{a}_{t}\left(z^{t}, \eta^{t}\right)+\gamma Y_{t}\left(z^{t}\right) \eta_{t}, \text { for all } z^{t}, \eta^{t}
\end{aligned}
$$

where $\hat{a}_{t}\left(z^{t}, \eta^{t}\right)$, the agent's net financial wealth in state $\left(z^{t}, \eta^{t}\right)$, is given by his state-contingent bond payoffs from bonds acquired last period, the payoffs from his equity position and the noncontingent bond payoffs:

$$
\hat{a}_{t}\left(z^{t}, \eta^{t}\right)=a_{t-1}\left(z^{t}, \eta^{t}\right)+s_{t}^{D}\left(z^{t-1}, \eta^{t-1}\right)\left[D_{t}\left(z^{t}\right)+V_{t}[\{D\}]\left(z^{t}\right)\right]+R_{t, t-1}[1]\left(z^{t-1}\right) b_{t-1}\left(z^{t-1}\right) .
$$

\subsection{Trading Technology}

A trading technology is a restriction on the menu of assets that the agent can trade in any given period. This includes restrictions on the frequency of trading as well. The set of asset trading technologies that we consider can be divided into two main classes: Mertonian trading technologies and non-Mertonian trading technologies.

Agents with a Mertonian or active trading technology optimally choose their portfolio composition given the menu of assets that they are allowed to trade in each period and given the state of the investment opportunity set. They can trade a complete menu of state-contingent securities with payoffs contingent on aggregate but not idiosyncratic shocks, in addition to non-contingent debt and equity. Hence we refer to these as z-complete traders.

For all non-Mertonian trading technologies, the menu of traded assets only consists of noncontingent debt and equity claims. A non-Mertonian trading technology also specifies an exogenously assigned and fixed target $\varpi^{\star}$ for the equity share. We refer to these traders as non-Mertonian precisely because the target does not respond to changes in the investment opportunity set. 
There are two types of these traders. A continuous-rebalancer adjusts his equity position to the target $\varpi^{\star}$ in each period. ${ }^{5}$ An intermittent-rebalancer adjusts his equity position to the target only every $n$ periods; in non-rebalancing periods, all (dis-)savings occur through adjusting the holdings of the investor's risk-free asset. ${ }^{6}$

All households are initially endowed with a claim to their per capita share of both diversifiable and non-diversifiable income. In period 1, each agent's financial wealth is constrained by the value of their claim to tradeable wealth in the period 0 planning period, which is given by:

$$
(1-\gamma) V_{0}[\{Y\}]\left(z^{0}\right) \geq \sum_{z_{1}} Q\left(z_{1}, z^{0}\right) \hat{a}_{0}\left(z^{1}, \eta^{0}\right)
$$

where both $z^{0}$ and $\eta^{0}$ simply indicate the degenerate starting values for the stochastic income process. ${ }^{7}$

Finally, the households face exogenous limits on their net asset positions, or solvency constraints,

$$
\hat{a}_{t}\left(z^{t}, \eta^{t}\right) \geq 0
$$

Traders cannot borrow against their future labor income.

\subsection{Measurability Restrictions}

To capture these portfolio restrictions implied by the different trading technologies, we use measurability constraints (see Chien, Cole, and Lustig (2010) for a detailed discussion) on net wealth.

\footnotetext{
${ }^{5}$ One could think of this household delegating the management of its portfolio to a fund manager (see Abel, Eberly, and Panageas (2006))

${ }^{6}$ Abel, Eberly, and Panageas (2006) consider a portfolio problem in which the investor pays a cost to observe her portfolio, and they show that even small costs can rationalize fairly large intervals in which the household does not check its portfolio, and finances its consumption out of the riskless account. We do not endogenize the decision to observe the value of the portfolio, but, instead, we focus on the aggregate equilibrium implications of what Abel, Eberly, and Panageas (2006) call 'stock market inattention'. However, we assume that our investor knows the value of his holdings when making consumption decisions, even in non-rebalancing periods. Hence, we are implicitly assuming that it is the cost of reallocating his portfolio that is preventing continuous adjustment rather than the cost of finding out about the value of his portfolio.

${ }^{7}$ In the quantitative analysis we only look at the ergodic equilibrium of the economy; hence, the assumptions about initial wealth are largely irrelevant. We assume that, during the initial trading period, households with portfolio restriction sell their claim to diversifiable income in exchange for their type appropriate fixed weighted portfolio of bonds and equities.
} 
These restrictions allow us to solve for equilibrium allocations and prices without having to search for the equilibrium prices that clear each security market.

Z-complete Mertonian Trader Since idiosyncratic shocks are not spanned for the z-complete trader, his net wealth needs to satisfy:

$$
\hat{a}_{t}\left(z^{t},\left[\eta_{t}, \eta^{t-1}\right]\right)=\hat{a}_{t}\left(z^{t},\left[\tilde{\eta}_{t}, \eta^{t-1}\right]\right)
$$

for all $t$ and $\eta_{t}, \tilde{\eta}_{t} \in N$.

Continuous-Rebalancing Non-Mertonian ( $\boldsymbol{c} \boldsymbol{r} \boldsymbol{b})$ Trader Non-Mertonian traders who rebalance their portfolio in each period to a fixed fraction $\varpi^{\star}$ in levered equity and $1-\varpi^{\star}$ in non-contingent bonds earn a return:

$$
R_{t}^{c r b}\left(\varpi^{\star}, z^{t}\right)=\varpi^{\star} R_{t, t-1}[\{D\}]\left(z^{t}\right)+\left(1-\varpi^{\star}\right) R_{t, t-1}[1]\left(z^{t-1}\right)
$$

Hence, their net financial wealth satisfies this measurability restriction:

$$
\frac{\hat{a}_{t}\left(\left[z_{t}, z^{t-1}\right],\left[\eta_{t}, \eta^{t-1}\right]\right)}{R_{t}^{c r b}\left(\varpi^{\star},\left[z_{t}, z^{t-1}\right]\right)}=\frac{\hat{a}_{t}\left(\left[\tilde{z}_{t}, z^{t-1}\right],\left[\tilde{\eta}_{t}, \eta^{t-1}\right]\right)}{R_{t}^{c r b}\left(\varpi^{\star},\left[\tilde{z}_{t}, z^{t-1}\right]\right)}
$$

for all $t, z_{t}, \tilde{z}_{t} \in Z$, and $\eta_{t}, \tilde{\eta}_{t} \in N$. If $\varpi^{\star}=1 /(1+\psi)$, then this trader holds the market in each period and earns the return on a claim to all tradeable income: $R_{t, t-1}[\{(1-\gamma) Y\}]\left(z^{t}\right)$. Without loss of generality, we can think of non-participants as $c r b$ traders with $\varpi^{\star}=0$.

Intermittent-Rebalancing Non-Mertonian (irb) Trader An irb trader's technology is defined by his portfolio target $\left(\right.$ denoted $\varpi^{\star}$ ) and the periods in which he rebalances (denoted $\mathcal{T}$ ). We assume that rebalancing takes place at fixed intervals. For example, if he rebalances every other period, then $\mathcal{T}=\{1,3,5, \ldots\}$ or $\mathcal{T}=\{2,4,6, \ldots\}$.

We define the trader's equity holdings as $e_{t}\left(z^{t}, \eta^{t}\right)=s_{t}^{D}\left(z^{t}, \eta^{t}\right) V_{t}[\{D\}]\left(z^{t}\right)$. In re-balancing 
periods, this trader's equity holdings satisfy:

$$
\frac{e_{t}\left(z^{t}, \eta^{t}\right)}{e_{t}\left(z^{t}, \eta^{t}\right)+b_{t}\left(z^{t}, \eta^{t}\right)}=\varpi^{\star}
$$

However, in non-rebalancing periods, the implied equity share is given by $\varpi_{t}=e_{t} /\left(e_{t}+b_{t}\right)$ where $e_{t}$ evolves according to the following law of motion:

$$
e_{t}\left(z^{t}, \eta^{t}\right)=e_{t-1}\left(z^{t-1}, \eta^{t-1}\right) R_{t, t-1}[\{D\}]\left(z^{t}\right)
$$

for each $t \notin \mathcal{T}$. This assumes that the $i r b$ trader automatically re-invests the dividends in equity in non-rebalancing periods.

After non-rebalancing periods, the irb trader with an equity share $\varpi_{t-1}$ earns a rate of return:

$$
R_{t}^{i r b}\left(\varpi_{t-1}, z^{t}\right)=\varpi_{t-1}\left(z^{t-1}\right) R_{t, t-1}[\{D\}]\left(z^{t}\right)+\left(1-\varpi_{t-1}\left(z^{t-1}\right)\right) R_{t, t-1}[1]\left(z^{t-1}\right)
$$

In all periods, rebalancing and non-rebalancing alike, he faces the following measurability restriction on net wealth:

$$
\frac{\hat{a}_{t}\left(\left[z_{t}, z^{t-1}\right],\left[\eta_{t}, \eta^{t-1}\right]\right)}{R_{t}^{i r b}\left(\varpi_{t-1},\left[z_{t}, z^{t-1}\right]\right)}=\frac{\hat{a}_{t}\left(\left[\tilde{z}_{t}, z^{t-1}\right],\left[\tilde{\eta}_{t}, \eta^{t-1}\right]\right)}{R_{t}^{i r b}\left(\varpi_{t-1},\left[\tilde{z}_{t}, z^{t-1}\right]\right)}
$$

for all $t, z_{t}, \tilde{z}_{t} \in Z$, and $\eta_{t}, \tilde{\eta}_{t} \in N$, with $\varpi_{t}=\varpi^{\star}$ in rebalancing periods.

Since setting $\mathcal{T}=\{1,2,3, \ldots\}$ generates the continuous-rebalancer's measurability constraint, the continuous-rebalancer can simply be thought of as a degenerate case of the intermittentrebalancer. Hence, we can state without loss of generality that a non-Mertonian trading technology is completely characterized by $\left(\varpi^{\star}, \mathcal{T}\right)$.

\subsection{Equilibrium}

We assume there is always a non-zero measure of z-complete traders to guarantee the uniqueness of the stochastic discount factor. For Mertonian traders, we let $\mu_{z}$ denote the measure of z-complete traders. For non-Mertonian traders, we denote the measure of $i r b(c r b)$ traders with $\mu_{i r b}\left(\mu_{c r b}\right)$ 
and their portfolio target with $\varpi^{\star}$; for nonparticipants, we use $\mu_{n p}$ to denote their measure. The portfolio target of non-participants is equal to zero.

The non-state-contingent bond market clearing condition is given by

$$
\sum_{\eta^{t}}\left[\begin{array}{c}
\mu_{z} b_{t}^{z}\left(z^{t}, \eta^{t}\right)+\mu_{c r b} b_{t}^{c r b}\left(z^{t}, \eta^{t}\right) \\
+\mu_{i r b} b_{t}^{i r b}\left(z^{t}, \eta^{t}\right)+\mu_{n p} b_{t}^{n p}\left(z^{t}, \eta^{t}\right)
\end{array}\right] \pi\left(\eta^{t} \mid z^{t}\right)=V[\{(1-\gamma) Y-D\}]\left(z^{t}\right)
$$

and the equity market clearing condition is given by

$$
\sum_{\eta^{t}}\left[\begin{array}{c}
\mu_{z} e_{t}^{z}\left(z^{t}, \eta^{t}\right)+\mu_{i r b} e_{t}^{i r b}\left(z^{t}, \eta^{t}\right) \\
+\mu_{c r b} e_{t}^{c r b}\left(z^{t}, \eta^{t}\right)
\end{array}\right] \pi\left(\eta^{t} \mid z^{t}\right)=V[\{D\}]\left(z^{t}\right)
$$

where we index the holdings of the z-complete traders, continuous rebalancers, intermittent rebalancers and non-participants respectively by $\{z, c r b, i r b, n p\}$.

For the sake of clarity, we use (e.g.) $\eta^{t-1}\left(\eta^{t}\right)$ to denote the history from zero to $t-1$ contained in $\eta^{t}$. We use the same convention for the aggregate histories. Using this notation, the market clearing condition in the state-contingent bond market is given by:

$$
\sum_{\eta^{t}}\left[\mu_{z} a_{t-1}^{z}\left(z^{t}, \eta^{t-1}\left(\eta^{t}\right)\right)\right] \pi\left(\eta^{t} \mid z^{t}\right)=0
$$

An equilibrium for this economy is defined in the standard way. It consists of a list of bond and dividend claim holdings, a consumption allocation and a list of bond and tradeable output claim prices such that: (i) given these prices, a trader's asset and consumption choices maximize her expected utility subject to the budget constraints, the solvency constraints and the measurability constraints, and (ii) the asset markets clear (eqs. (10), (11),(12)).

We solve a time zero Arrow-Debreu version of the household problem subject to these additional measurability restrictions. We develop an extension of the multiplier method developed by Chien, Cole, and Lustig (2010) to handle intermittent rebalancers. Section A in the appendix contains a 
detailed description of the solution algorithm. ${ }^{8}$

\subsection{The Importance of Rebalancing}

To explain the importance of rebalancing for aggregate risk sharing, we look at a version of our economy in which aggregate consumption growth is not predictable:

$$
\phi\left(z^{\prime} \mid z\right)=\phi\left(z^{\prime}\right)
$$

and the distribution of idiosyncratic shocks is independent of aggregate shocks:

$$
\pi\left(\eta^{\prime} \mid \eta, z\right) / \phi\left(z^{\prime}\right)=\varphi\left(\eta^{\prime} \mid \eta\right)
$$

Suppose that the non-Mertonian traders belong to the class of continuous-rebalancers $(c r b)$, and suppose that they hold the market portfolio: their target share is $\varpi^{\star}=1 /(1+\psi)$. Also, suppose that there are no non-participants in this economy. The $c r b$ trader can choose a consumption path that is proportional to aggregate output:

$$
c_{t}\left(z^{t}, \eta^{t}\right)=\widehat{c}_{t}\left(\eta^{t}\right) Y\left(z^{t}\right)
$$

where the share $\widehat{c}_{t}$ does not depend on the history of aggregate shocks $z^{t}$. This particular consumption path in eq. (15) is feasible for the non-Mertonian trader simply by trading a claim to aggregate consumption (the market), .i.e., maintaining a portfolio with $\varpi^{\star}=1 /(1+\psi)$ invested in equity. There is in fact an equilibrium in which all agents only trade claims to aggregate con-

\footnotetext{
${ }^{8}$ In continuous-time finance, Cuoco and He (2001) and Basak and Cuoco (1998) used stochastic weighting schemes to characterize allocations and prices. Our approach differs because it provides a tractable and computationally efficient algorithm for computing equilibria in environments with a large number of agents subject to idiosyncratic risk as well as aggregate risk, and heterogeneity in trading technologies. The use of cumulative multipliers in solving macro-economic equilibrium models was pioneered by Kehoe and Perri (2002), building on earlier work by Marcet and Marimon (1999). Our use of measurability constraints to capture portfolio restrictions is similar to that in Aiyagari, Marcet, Sargent, and Seppala (2002) and Lustig, Sleet, and Yeltekin (2007), who consider an optimal taxation problem, while the aggregation result extends that in Chien and Lustig (2010) to an incomplete markets environment.
} 
sumption, as shown by Krueger and Lustig (2009). In this equilibrium, the equity premium is the Breeden-Lucas-Rubenstein representative agent equity premium, because all households bear the same amount of aggregate risk.

However, for an irb trader, this particular consumption path is not feasible, because holding the market requires re-balancing every period. Instead, consider what happens to an irb trader who starts out by holding the aggregate consumption claim in his portfolio.

After a negative aggregate consumption growth shock $z_{t}$, the equity share of the average irb portfolio drops below $1 /(1+\psi)$, and the average non-Mertonian trader holds too little equity. After a positive aggregate consumption growth shock $z_{t}$, the equity share of the average $i r b$ portfolio increases above $1 /(1+\psi)$, and the non-Mertonian trader holds too much equity.

To see why, note that the $\mathrm{p} / \mathrm{d}$ ratio is constant in the original equilibrium; there is no predictability in either dividend growth or future returns. If the $\mathrm{p} / \mathrm{d}$ ratio is constant, then the average agent should simply consume the dividends to hold the market portfolio. The equity share in his portfolio remains constant at $1 /(1+\psi)$ if he does so. Instead, the average irb trader buys more shares than usual after high aggregate consumption shocks and buys fewer shares than usual after low aggregate consumption growth shocks.

Why? Consider the case in which $1 / 3$ of irb traders rebalances each period. Let us start with irb traders who do not rebalance in that period. They account for $2 / 3$ of all irb traders in the calibrated model. The $2 / 3$ of irb traders who do not rebalance that period re-invest the dividends automatically. Hence, they buy more shares after good aggregate consumption growth shocks than after bad aggregate consumption growth shocks. ${ }^{9}$ Moreover, the $1 / 3$ of $i r b$ traders who do rebalance do not offset this cyclical buying of shares, because they have a fixed equity target.

As a result, the active traders as a group sell more shares than usual after high aggregate consumption growth realizations to the irb traders and they buy more shares than usual after low aggregate consumption growth realizations. Thus, after a series of negative aggregate consumption growth shocks, the $i r b$ 's equity share $\varpi_{t-1}$ would be much lower than what is required to hold the

\footnotetext{
${ }^{9}$ The $i r b$ traders who do not rebalance in a period almost always buy shares because dividends are almost always positive. What matters for our mechanism is the cyclical variation in the buying of shares.
} 
market, and $R_{t}^{i r b}\left(\varpi_{t-1}, \tilde{z}_{t}\right)$ is increasingly less exposed to aggregate consumption risk. In this new

equilibrium, the relative wealth of the non-Mertonian $i r b$, traders $\widehat{A}_{t}^{i r b}\left(z^{t}\right) / \sum_{j \in\{z, i r b\}} \widehat{A}_{t}^{j}\left(z^{t}\right)$ cannot be invariant w.r.t aggregate shocks.

Hence, these intermittent rebalancers act like households with counter-cyclical risk aversion, because of the nature of the trading technology: adverse aggregate shocks endogenously concentrate aggregate risk among the Mertonian traders. This destroys the constant representative agent equity premium result even in the case of i.i.d. aggregate shocks without non-participants. The p/d ratio cannot be constant in equilibrium. The risk premium has to increase after bad shocks and decrease after good shocks.

In the calibrated version of the model that we present in the next section, we introduce another friction: non-participants. These non-participants create residual aggregate risk that needs to be transferred to the other market participants. This concentration of aggregate risk allows us to match the average equity premium.

\section{Calibration}

Section 5 evaluates a calibrated version of the model to examine the extent to which our model can account for the empirical moments of asset prices, and in particular the counter-cyclical volatility at market price of risk. This section discusses the calibration of the parameters and the endowment processes, and the composition of trader pools.

To compute the equilibrium of this economy, we follow the algorithm described by Chien, Cole, and Lustig (2010), who use truncated aggregate histories as state variables. We keep track of lagged aggregate histories up to 7 periods. The details are in section $\mathrm{C}$ of the appendix.

Our objective is to examine the response of the moments of equilibrium asset prices, consumption growth, portfolio returns and the welfare to changes in the frequency of rebalancing by non-Mertonian equity holders and the level of their equity target. 


\subsection{Preferences and Endowments}

The model is calibrated to annual data. We set the coefficient of relative risk aversion $\alpha$ to five and the time discount factor $\beta$ to .95. These preference parameters allow us to match the collaterizable wealth to income ratio in the data when the tradeable or collateralizable income share $1-\gamma$ is $10 \%$, as discussed below. The average ratio of household wealth to aggregate income in the US is 4.30 between 1950 and 2005. The wealth measure is total net wealth of households and non-profit organizations (Flow of Funds Tables). With a 10\% collateralizable income share, the implied ratio of wealth to consumption is 5.28 in the model's benchmark calibration. ${ }^{10}$

Our benchmark model is calibrated to match the aggregate consumption growth moments from Alvarez and Jermann (2001) and Mehra and Prescott (1985). The average consumption growth rate is $1.8 \%$ and the standard deviation is $3.15 \%$. Recessions are less frequent than expansions: $27 \%$ of realizations are low aggregate consumption growth states. The first-order autocorrelation coefficient of aggregate consumption growth $\left(\rho_{z}\right)$ is -.14. We will refer to this as the Mehra-Prescott (MP) Economy henceforth.

We also consider a second calibration without any predictability of aggregate consumption growth. This i.i.d consumption process is the same one as described in subsection 3.6. In this calibration, we simply set the autocorrelation of aggregate consumption growth $\left(\rho_{z}\right)$ to zero, but we keep all others moments are unchanged. We refer to this calibration as IID Economy.

We calibrate the labor income process as in Storesletten, Telmer, and Yaron (2004) and Storesletten, Telmer, and Yaron (2007), except that we eliminate the counter-cyclical variation of labor income risk. The variance of labor income risk is constant in our model. This allows us to focus on the effects of changes in composition of non-Mertonian traders pool and their target equity share. The Markov process for $\log \eta(y, z)$ has a standard deviation of 0.71 , and the autocorrelation is 0.89 . We use a 4-state discretization for both aggregate and idiosyncratic risk. The elements of the process for $\log \eta$ are $\{0.38,1.61\}$.

\footnotetext{
${ }^{10}$ As is standard in this literature, we compare the ratio of total outside wealth to aggregate non-durable consumption in our endowment economy to the ratio of total tradeable wealth to aggregate income in the data. Aggregate income exceeds aggregate non-durable consumption because of durable consumption and investment.
} 
Equity in our model is simply a leveraged claim to diversifiable income. In the Flow of Funds, the ratio of corporate debt-to-net worth is around 0.65, suggesting a leverage parameter $\psi$ of 2 . However, Cecchetti, Lam, and Mark (1990) report that standard deviation of the growth rate of dividends is at least 3.6 times that of aggregate consumption, suggesting that the appropriate leverage level is over 3. Following Abel (1999) and Bansal and Yaron (2004), we choose to set the leverage parameter $\psi$ to 3 .

\subsection{Composition of Trader Pools and Equity Share}

In the most recent Survey of Consumer Finances, $51.1 \%$ of households reported owning stocks directly or indirectly. Therefore, the fraction of non-Mertonian traders with zero equity holding (non-participants) is calibrated to $50 \%$. In order to match the large equity premium $(7.53 \%)$ measured in post-war US data, a small fraction of Mertonian traders need to bear the residual aggregate risk created by non-participant. Hence, we set the share of Mertonian traders equal to $5 \%$, and non-Mertonian traders who hold equities to $45 \%$.

We consider two types of non-Mertonian equity holders: (1) those who rebalance every period $(c r b)$ and (2) those who rebalance every 3 years $(i r b)$. This level of inertia is modest compared to what researchers have documented in the data (see, e.g., the evidence reported by Ameriks and Zeldes (2004), Calvet, Campbell, and Sodini (2009) and Brunnermeier and Nagel (2008)). We assume that an equal fraction of irb traders rebalances every period.

In the case with $i r b$ traders, the optimal target equity share of $i r b$ traders turns out to be 37 $\%$ in the MP economy and $42 \%$ in the IID economy. Hence, these cases are natural benchmarks to consider. To evaluate the effects of changes in equity share, we consider three additional equity share targets for our non-Mertonian equity holders: 30\%, 35\%, and $40 \%$.

\section{Quantitative Results in Benchmark Economy}

Table I reports moments of asset prices generated by simulating data from a model with 3,000 agents for 10,000 periods. Panel I and II report results for the case of MP economy and IID 
economy respectively. Each panel consists of two cases: one with $45 \%$ crb trader and the other with $45 \%$ irb trader.

\subsection{Asset Prices}

In the upper part of Table I, we report the maximum unconditional Sharpe ratio or market price of risk $\left(\frac{\sigma(m)}{E(m)}\right)$, the standard deviation of the maximum $\operatorname{SR}\left(\operatorname{Std}\left(\frac{\sigma_{t}(m)}{E_{t}(m)}\right)\right)$, the equity risk premium $E\left(R_{t+1, t}[D]-R_{t+1, t}[1]\right)$, the standard deviation of excess returns $\sigma\left(R_{t+1, t}[D]-R_{t+1, t}[1]\right)$, the Sharpe ratio on equity, the mean risk-free rate $E\left(R_{t+1, t}[1]\right)$ and the standard deviation of the risk-free rate $\sigma\left(R_{t+1, t}[1]\right)$. In the lower part of Table I, we report the standard deviation of the conditional risk premium on equity $\operatorname{Std}\left[E_{t}\left(R_{t+1, t}[D]-R_{t+1, t}[1]\right)\right]$, the standard deviation of the conditional volatility of risk premium on equity $\operatorname{Std}\left[\sigma_{t}\left(R_{t+1, t}[D]-R_{t+1, t}[1]\right)\right]$ and the standard deviation of the conditional SR on equity $S t d\left[S R_{t}\right]$.

CRB In the case with $c r b$ traders, the maximum SR is 0.39 and the standard deviation of the maximum $\mathrm{SR}$ is $8.22 \%$. The equity premium is $8.48 \%$ and the Sharpe ratio on equity is .38. The average risk-free rate is $1.53 \%$ and its volatility is $2.80 \%$. Finally, we also decompose the variation in the SR on equity; the standard deviation of the conditional risk premium on equity is $1.63 \%$, the standard deviation of the conditional volatility is $1.68 \%$ and this produces a standard deviation of the conditional $\mathrm{SR}$ is $8.22 \%$.

IRB In the case with irb traders, the maximum SR is 0.41 and the standard deviation of the maximum SR is $25.25 \%$. This represents a threefold increase in the volatility. The equity premium drops to $7.85 \%$ while the standard deviation of stock returns increases to $27.67 \%$. The Sharpe ratio on equity drops to .28. The moments of the risk-free rate are virtually unchanged. So, while the unconditional risk premia are lower in the economy with intermittent rebalancing, the volatility of conditional risk premia triples, and the behavior of interest rates is largely unaffected.

The intermittent rebalancing behavior also increases the volatility of conditional moments on equity returns significantly. The standard deviation of the conditional risk premium increases from 
$1.63 \%$ to $5.99 \%$, the standard deviation of the conditional volatility increases from 1.68 to $3.20 \%$, and the standard deviation of the conditional SR on equity increases from $8.22 \%$ to $26.23 \%$.

Approximation The last line in Table I reports the standard deviation of the allocation error that results from our approximation in percentage points. The standard deviation of the percentage forecast error is between $0.14 \%$ and $0.07 \%$ in the benchmark cases. This means that our approximation is highly accurate compared to other results reported in the literature for models with heterogeneous agents and incomplete markets. The implied $R^{2}$ in a linear regression of the actual realization of the SDF's on the SDF that we predicted based on the truncated aggregate histories exceed 0.998 in all cases.

[Table 1 about here.]

Economy with IID Aggregate Consumption Growth Dynamics Alvarez and Jermann (2001) match the first-order autocorrelation of aggregate consumption growth shocks $\left(\rho_{z}=-.14\right)$ reported by Mehra and Prescott (1985). We check the sensitivity of our results to the negative autocorrelation of aggregate consumption growth shocks by choosing an IID calibration of aggregate consumption growth shocks $\left(\rho_{z}=0\right)$, and we compare our model quantitatively to Campbell and Cochrane (1999) with the same aggregate consumption growth process. This IID economy satisfies the assumptions we imposed in the IID example (see subsection 3.6). In this version of model, without non-participants, the representative agent risk premium is obtained if all non-Mertonian traders are of $c r b$ type. Furthermore, this risk premium is constant. Hence, in this case, we know that all of the dynamics are generated by the intermittent rebalancers.

The key moments of the stochastic discount factor are reported in Panel II of Table I. If the irb traders hold the optimal equity share (42\%), the volatility increases from $6.35 \%$ to $15.11 \%$. This represents an increase of $238 \%$, somewhat smaller than the increase reported in the non-IID economy. In any case, the volatility is always lower in IID economy but the $i r b$ traders still amplify the volatility of the market prices of risk significantly.

To help assess the strength of our mechanism, we can use the implied standard deviation of the 
market price of risk in an annual calibration of the Campbell and Cochrane (1999) external habit model as a benchmark, with the same i.i.d aggregate consumption growth process as in our IID economy. All of the other parameters are taken directly from Campbell and Cochrane (1999). In this annual calibration of their model, the standard deviation of the market price of risk is $21 \%$. In our benchmark IID economy with CRRA (constant relative risk aversion) agents, our model generates $15.11 \%, 1 / 4$-th less than the external habits model. However, as we shall show in section 6 , the volatility generated by our model increases to $23.20 \%$ if Mertonian traders can hedge against their idiosyncratic risk, slightly higher than the volatility produced by the external habits model.

Reinvestment of Dividends Our results critically rely on our assumption that the irb traders reinvest the dividends in non-rebalancing periods. In the benchmark case of MP economy, the standard deviation of the market price of risk actually drops from $8.22 \%$ to $6.63 \%$ in the irb case without reinvestment of dividends (not shown in Table). Recall that with reinvestment the volatility increases to $25.25 \%$.

Without intermittent rebalancers, our model does not generate much variation in the price/dividend ratio, and hence, most of the effects have to come from the reinvestment of dividends. Therefore, if the dividends are not reinvested and the price/dividend ratio is constant, there is really no need for the irb traders to rebalance. There is no net new issuance of shares at the aggregate level. In equilibrium, the average investor simply consumes his or her dividends. There is no need for trade in shares between the average non-Mertonian and the average Mertonian trader. Once the irb trader reinvests dividends, then the Mertonian traders have to sell shares after good aggregate shocks and buy shares after bad aggregate shocks.

Figure 2 plots a 100-year simulation of the equity share (full line) of the Mertonian trader in the case with irb traders in the top panel; the bottom panel shows the case with $c r b$ traders. The shaded areas are low aggregate consumption growth states, and the dashed line is a 4-period moving average of aggregate consumption growth. Clearly, there is much more counter-cyclical variation in the equity share of the Mertonian traders in the irb case, especially on the downside. This variation in the equity share of the Mertonian traders is the driving force behind our amplification 
mechanism.

[Figure 2 about here.]

Countercyclical Variation The variation in market price of risk created by the $i r b$ traders is counter-cyclical; it mirrors the variation in the active trader's equity share. Figure 3 plots the conditional Sharpe ratio on equity against the history of aggregate consumption growth shocks for the benchmark case of MP economy. The shaded areas denote the low aggregate consumption growth realizations. The dotted line shows 4-period moving average of aggregate consumption growth; the full line shows the conditional Sharpe ratio.

[Figure 3 about here.]

In the $i r b$ case, the conditional risk premium on equity increases with each low aggregate consumption growth realization, and decreases with each high aggregate consumption growth realization. The conditional Sharpe ratio on equity is even more counter-cyclical, because the conditional volatility decreases with each negative aggregate consumption growth realization (not shown in the picture). Figure 4 shows this in a scatter plot representation of the same 100 simulations, with the weighted average of aggregate consumption growth shocks on the $\mathrm{x}$-axis and the conditional Sharpe ratio. On the other hand, in the $c r b$ case, shown in figure 5, the conditional Sharpe ratio is only weakly counter-cyclical.

[Figure 4 about here.]

[Figure 5 about here.]

\subsection{Portfolio, Wealth, Consumption and Welfare Costs}

The first panel in Table II reports the moments of household portfolio returns in benchmark case of MP economy. In the irb case, the Mertonian z-complete traders realize an excess return of $6.02 \%$ and a SR of 0.51 , compared to only $2.72 \%$ and 0.26 respectively for the $i r b$ trader. The optimal 
average portfolio share for a non-Mertonian $c r b$ trader is only $51 \%$ (compared to $72 \%$ in the $c r b$ case), because the equity premium is lower.

We also evaluate the welfare cost of being a non-Mertonian $c r b$ or $i r b$ trader. This cost is measured by the percentage of consumption compensation to Mertonian traders so that they are indifference to become non-Mertonian traders. Given the optimal equity share target in each case, the welfare cost of being a non-Mertonian irb trader in irb case is 4 times higher than that in the crb case $(11.94 \%$ v.s. $2.66 \%)$ because the risk premium is much more volatile and hence the cost of not responding to variation in the investment opportunity set is much larger.

We also report the welfare cost of being an irb trader compared to a $c r b$ trader holding fixed the equity share target at $37 \%$. The cost is small $(-1.23 \%)$ and negative: a $c r b$ trader would be willing to yield $1.23 \%$ of his consumption to become an irb trader. This is surprising, but it has a simple reason. The optimal equity target of $c r b$ trader is $51 \%$, which is higher than the optimally chosen target for the $i r b$ trader, $37 \%$. Hence, increasing the equity share actually benefits the $c r b$ trader because of high average equity premium. The average equity share holding of $i r b$ traders is actually higher than his target equity share because expansions are more frequent than recessions and because their equity share drifts up in expansions. As it turns out, this benefit outweighs the cost of intermittent rebelancing. ${ }^{11}$

On the other hand, an irb trader -setting his target share optimally- would be willing to pay $2.7 \%$ of consumption to become a $c r b$ trader who can optimally choose his target. This number is the difference between $11.9 \%$ (reported as the welfare cost $(\%)$ of $i r b$ to $z$ at the optimal equity share for $\mathrm{irb}$ ) and $9.2 \%$ in Table II (reported as the welfare cost(\%) of $c r b$ to $z$ at the optimal equity share for $c r b$ ). This $2.7 \%$ number is the true cost of not rebalancing. It is small relative to the cost of not responding to changes in the investment opportunity set. The costs of not rebalancing are small; the costs of having a fixed equity target are large.

The second panel in Table II reports the moments of household consumption growth, and the moments of aggregate consumption growth for each group of traders. In the $c r b$ case, the volatility

\footnotetext{
${ }^{11}$ However, if we force the average equity shares to be the same for these traders, the cost would obviously be positive. In any case, this shows that the direct cost of intermittent rebalancing has to be small, much smaller than the cost of being a non-Mertonian.
} 
of household consumption growth is inversely related to the degree of sophistication of the trader: $3.12 \%$ for Mertonian traders, 3.33\% for the $c r b$ traders and 3.76\% for non-participants. However, the relation between consumption volatility and trader sophistication reverses itself at the group level. The volatility for the Mertonian trader segment is $1.85 \%$, compared to $1.19 \%$ for the nonMertonian equity holders, and $0.60 \%$ for the non-participants. These results highlight the fact that these traders are exposed to different types of risk. Mertonian traders are more exposed to aggregate risk, and non-Mertonian traders are more subject to idiosyncratic risk.

Now, in the case of the irb traders, the volatility of the Mertonian trader's consumption growth (at the group level) decreases to $1.80 \%$, while, at the household level, the volatility of household consumption growth for non-Mertonian equity holders increases from $3.33 \%$ to $3.88 \%$. Other than that, the second moment of consumption is very similar to $c r b$ case at both individual and group level.

Overall, what is striking is how similar the unconditional moments are in the case of $c r b$ and irb traders, both in terms of portfolio returns and household consumption. The main quantitative difference is the increase in the volatility of household consumption growth for the non-Mertonian equity holders.

Finally, the third panel in Table II reports the household wealth statistics. The Mertonian (zcomplete) trader accumulates 1.88 times as much wealth as the average household in the baseline crb case, while the non-Mertonian trader accumulates 1.19 times as much, and the non-participant only 0.74 times the average. These fractions are virtually unchanged in the $i r b$ case. However, the wealth of the non-Mertonian trader (expressed as a fraction of average wealth) becomes more volatile - it increases from $9.4 \%$ to $15.2 \%$.

Our model has reasonable cross-sectional consumption implications. In our model, Mertonian investors load up on aggregate consumption risk, earn higher portfolio return and end up richer. This is consistent with the data. The consumption of the $10 \%$ wealthiest households is 5 times more exposed to aggregate consumption growth than that of the average US household (Parker and Vissing-Jorgensen (2009)). Malloy, Moskowitz, and Vissing-Jorgensen (2009) find that the average 
consumption growth rate for stock-holders is between 1.4 and 2 times as volatile as that of nonstock holders. They also find that aggregate stockholder consumption growth for the wealthiest segment (upper third) is up to 3 times as sensitive to aggregate consumption growth shocks as that of non-stock holders.

[Table 2 about here.]

\subsection{Composition of the non-Mertonian Trader Pool and Equity Share}

The participation of non-Mertonian traders tends to increase the volatility in risk premia. In our

model, this mechanism operates in two ways: (i) as we shift non-Mertonian traders from the $c r b$ type to the $i r b$ type and (ii) as we increase the target share of equity in the non-Mertonian trader's portfolio. We discuss both of these effects below.

Table III varies the target equity share from $30 \%$ to $40 \%$. The first panel reports result for the case when the target equity share of the non-Mertonian trader $\varpi^{\star}$ is $30 \%$, the second panel considers the case of a 35\% target share, and finally, the last panel looks at the case of $40 \%$.

Increasing the target share of equity for Non-Mertonian equity traders also increases the volatility substantially, from $6.8 \%$ in the $c r b$ case $(17.3 \%$ in the $i r b$ case), with $30 \%$ target equity share (see left panel of Table III), to $10.02 \%$ (24.80\%) with $40 \%$ target share (see right panel of Table III). However, as we increase the equity holdings of the non-Mertonian equity traders from $30 \%$ to $40 \%$, the unconditional market price of risk, the equity premium and Sharpe ratio all decrease. The more equity non-Mertonian traders hold, the higher is the volatility of risk prices. A 10 percentage point increase in the target share for equities delivers a $50 \%$ increase in the volatility of risk prices. As we increase the target equity share to $40 \%$, the equity risk premium actually turns negative after a series of high aggregate consumption growth shocks. This explains why the volatility of the Sharpe ratio surpasses that of the market price of risk.

[Table 3 about here.] 


\section{Quantitative Results in Economy with Binding Solvency Constraints for Mertonian Traders}

While the results reported so far show that $i r b$ non-Mertonian traders amplify the volatility of risk prices, the numbers are still small compared to the $50 \%$ standard deviation of the SR reported by Lettau and Ludvigson (2001). However, the composition of the Mertonian trader pool is equally important for the volatility of the market price of risk. The z-complete Mertonian traders are subject to idiosyncratic risk and hence have a precautionary motive to accumulate wealth. As a result, their solvency constraints rarely bind in equilibrium. We now look at what happens when we introduce another type of Mertonian traders who are not subject to idiosyncratic risk or can hedge against it. We refer to this type of Mertonian trader as a complete trader. We can think of complete traders as a stand-in for highly levered, active market participants like hedge funds. These participants will tend to increase the volatility of risk premia if they are subject to occasionally binding solvency constraints (see Alvarez and Jermann (2001) and Chien and Lustig $(2010))$.

\subsection{Composition of the Mertonian Trader Pool}

The first panel of Table IV reports the result of MP economy with complete traders. As we change the Mertonian trader from z-complete traders to complete traders, the volatility of the market price of risk increases from $25.25 \%$ to $34.41 \%$ in our MP economy as shown in Table I and IV. Moreover, the volatility of the conditional Sharpe ratio on equity increases from $26.23 \%$ to $39.83 \%$. This means we get much closer to the target in the data if we introduce these complete Mertonian traders. Clearly, the binding solvency constraints strengthen our mechanism considerably.

Economy with IID Aggregate Consumption Growth Dynamics The second panel of Table IV reports the result for the IID economy. The volatility of the market price of risk is $23.20 \%$, which is comparable to that $(21 \%)$ in the annual calibration version of Campbell and Cochrane (1999) model. 
[Table 4 about here.]

In addition, these complete traders load up on more aggregate risk, as is apparent from the results in the first two panels of Table V. The complete traders realize average excess returns of up to $14 \%$ per annum. At the household level, in the baseline case with $c r b$ traders, we get the same relation between trader sophistication and consumption growth volatility: the standard deviation of household consumption growth is $2.39 \%$ for the Mertonian traders, compared to $3.25 \%$ for the non-Mertonian equity holders and $3.78 \%$ for the non-participants. However, the composition is very different: the group volatility is $2.10 \%$ for the Mertonian traders, compared to $1.22 \%$ for the non-Mertonian equity holders and .63\% for the non-participants. Finally, the welfare cost of being a non-Mertonian trader increases significantly from $11.94 \%$ to $25.15 \%$ because the volatility of risk premia is so much higher.

[Table 5 about here.]

For the same 100 simulations, we also plot the conditional Sharpe ratio against the weighted average of consumption growth shocks in Figure 6. The conditional SR declines monotonically as the weighted average of aggregate consumption growth shocks increases. The pattern here is similar to that in the case of z-complete traders, but with a larger amplitude. The range of variation increases from $[0.15,0.75]$ in the case with z-complete traders to $[0.1,1.2]$ in the case with complete traders. However, in the $c r b$ case, shown in Figure 7, this amplification is much smaller. It is the interaction of slow-moving capital supplied by intermittent rebalancers and fast-moving and highly levered capital subject to solvency constraints that generates the variation in the risk premia.

[Figure 6 about here.]

[Figure 7 about here.]

\subsection{Size of Mertonian Trader Pool}

The volatility of risk premia depends critically on the size of the Mertonian trader pool. We fix the target equity share at 37\% in MP economy. As we grow the size of the Mertonian trader pool, 
the volatility of the market price of risk decreases at a fast rate. Table VI reports the conditional moments in the case of a 10\% Mertonian trader pool (up from $5 \%$ in the benchmark case) in MP economy.

The first two columns report the case with z-complete traders. The amplification channel is still operative, but the effect is smaller. In the case with $10 \%$ z-complete traders, the volatility of the market price of risk is $5.2 \%$, and this number increases to $13.3 \%$ when we replace the $c r b$ traders with irb traders. In the benchmark case with only 5\% Mertonian traders, these numbers were $8.22 \%$ and $25.25 \%$ respectively, as reported in Table I. So, the amplification channel has weakened considerably. The standard deviation of the conditional Sharpe ratio on equity increases from $5.23 \%$ to $13.3 \%$, compared to an increase from $8.22 \%$ to $26.23 \%$ in the benchmark case with $5 \%$ Mertonian traders.

As the mass of z-complete traders increases, the amplification channel weakens partly because aggregate risk is not concentrated enough. This is mitigated when we replace these z-complete traders with complete traders because the latter have no precautionary motive to accumulate wealth. As a result, their solvency constraints bind in equilibrium. These results are reported in the last two columns of Table VI. In this case, the standard deviation of the market price of risk increases from $10.96 \%$ to $25.54 \%$, compared to $16.32 \%$ and $34.4 \%$ respectively in the benchmark case with only 5\% Mertonian traders. Therefore, the amplification channel is not mitigated as much as the case with z-complete trader by an increase in the supply of Mertonian trader.

[Table 6 about here.]

\section{Conclusion}

Our paper shows that slow-moving capital supplied by intermittent portfolio re-balancers should be considered as an important contributing factor to the puzzling volatility of Sharpe ratios in equity markets. Our welfare cost calculations suggest that small costs might suffice to deter households from continuously re-balancing. However, the aggregate impact on equilibrium asset prices is large. This makes it an appealing friction. 
On the other hand, the welfare costs of ignoring changes in the investment opportunity set are large in our model precisely because risk premia are so volatile. These welfare costs increase as fast-moving capital become less subject to idiosyncratic risk and faces more frequently binding solvency constraints. 


\section{References}

Abel, A. B. (1999): "Risk Premia and Term Premia in General Equilibrium," Journal of Monetary Economics, 43, 3-33.

Abel, A. B., J. C. Eberly, and S. Panageas (2006): "Optimal Inattention to the Stock Market," American Economic Review Papers and Proceedings, 97(2), 244-248.

Aiyagari, S. R., A. Marcet, T. J. Sargent, and J. Seppala (2002): "Optimal Taxation Without State-Contingent Debt," Journal of Political Economy, 110(6), 1220-1254.

Alvarez, F., L. Guiso, And F. Lippi (2010): "Durable consumption and asset management with transaction and observation costs.," Working Paper, University of Chicago.

Alvarez, F., and U. Jermann (2001): "Quantitative Asset Pricing Implications of Endogenous Solvency Constraints," Review of Financial Studies, 14, 1117-1152.

Ameriks, J., And S. P. Zeldes (2004): "How do Household Portfolio Shares Vary with Age?," Working Paper Columbia University.

Bansal, R., And A. Yaron (2004): "Risks for the Long Run: A Potential Resolution of Asset Prizing Puzzles," The Journal of Finance, 59, 1481-1509.

Barberis, N., M. Huang, and T. Santos (2001): "Prospect Theory and Asset Prices," Quarterly Journal of Economics, 116(1), 1-53.

Basak, S., And D. Cuoco (1998): "An Equilibrium Model with Restricted Stock Market Participation," Review of Financial Studies, 11(2), 309-341.

Boldrin, M., L. Christiano, and J. Fisher (2001): "Habit Persistence, Asset Returns, and the Business Cycle," American Economic Review, 91(1), 149-66.

Brunnermeier, M. K., and S. Nagel (2008): "Do Wealth Fluctuations Generate Time-Varying Risk Aversion? Micro-Evidence on Individuals' Asset Allocation," American Economic Review, $98: 3,713-736$. 
Calvet, L. E., J. Y. Campbell, and P. Sodini (2009): "Fight Or Flight? Portfolio Rebalancing By Individual Investors," The Quarterly Journal of Economics, February, 301-346.

Campbell, J. Y., and J. H. Cochrane (1999): "By Force of Habit: A Consumption-Based Explanation of Aggregate Stock Market Behavior," Journal of Political Economy, 107(2), 205251.

Cecchetti, S. G., P.-S. Lam, and N. C. Mark (1990): "Mean Reversion in Equilibrium Asset Prices," American Economic Review, Vol. 80, No. 3, 398-418.

Chan, Y. L., and L. Kogan (2002): "Catching Up With the Joneses: Heterogeneous Preferences and the Dynamics of Asset Prices," Journal of Political Economy, 110, 1255-1285.

Chien, Y., H. Cole, and H. Lustig (2010): "A Multiplier Approach to Understanding the Macro Implications of Household Finance," Review of Economic Studies, forthcoming, Available at SSRN: http://ssrn.com/abstract=1023184.

Chien, Y., And H. Lustig (2010): "The Market Price of Aggregate Risk and the Wealth Distribution," Review of Financial Studies, 23(4), 1596-1650.

Constantinides, G. M. (1990): "Habit-formation: A Resolution of the Equity Premium Puzzle," Journal of Political Economy, 98, 519-543.

Cuoco, D., And H. He (2001): "Dynamic Equilibrium in Infinite Dimensional Economies with Incomplete Financial Markets," Annals of Economics and Finance, 2, 265-296.

Detemple, J., And S. Murthy (1997): "Equilibrium asset prices and no-arbitrage with portfolio constraints," Review of Financial Studies, 10, 1133-1174.

Doms, M., And N. Morin (2004): "Consumer Sentiment, the Economy, and the News Media," FRBSF Working Paper, 2004-09.

Duffie, D. (2010): "Asset Price Dynamics with Slow-Moving Capital," Journal of Finance, forthcoming, 2010 Presidential Address to the American Finance Association. 
Duffie, D., And T.-S. Sun (1990): "Transactions Costs And Portfolio Choice In A DiscreteContinuous-Time Setting," Journal of Economic Dynamics and Control, 14, 35-51.

Gabaix, X., And D. Laibson (2002): "The 6D Bias and the Equity Premium Puzzle," NBER Macroeconomics Annual, pp. 257-312.

Garleanu, N., and S. Panageas (2007): "Young, Old, Conservative and Bold: The Implications of Heterogeneity and Finite Lives for Asset Pricing," Working Paper Wharton.

Gomes, F., And A. Michaelides (2008): "Asset Pricing with Limited Risk Sharing and Heterogeneous Agents," Review of Financial Studies, 21(1), 415-448.

Grossman, G., and G. Laroque (1990): "Asset Pricing and Optimal Portfolio Choice in the Presence of Illiquid Durable Consumption Goods.," Econometrica, 58(1), 25-51.

Guvenen, F. (2009): "A Parsimonious Macroeconomic Model for Asset Pricing," Econometrica, $77(6), 1711-1750$.

Jermann, U. (1998): "Asset Pricing in Production Economies," Journal of Monetary Economics, pp. $257-275$.

Kehoe, P. J., And F. Perri (2002): "International Business Cycles with Endogenous Incomplete Markets," Econometrica, 70(3), 907-928.

Krueger, D., And H. Lustig (2009): "When is Market Incompleteness Irrelevant for the Price of Aggregate Risk (and When is it Not)?," Journal of Economic Theory, 145(1), 1-41.

Lettau, M., and S. C. Ludvigson (2001): "Measuring and Modeling Variation in the RiskReturn Tradeoff," Unpublished paper, New York University.

Lintner, J. (1965): "Security Prices, Risk and Maximal Gains from Diversification," Journal of Finance, 20, 587-615.

Lustig, H., C. Sleet, And S. Yeltekin (2007): "Fiscal hedging with nominal assets," Journal of Monetary Economics, 55(4), 710-727. 
LyNCH, A. W. (1996): "Decision Frequency and Synchronization Across Agents: Implications for Aggregate Consumption and Equity Return," The Journal of Finance, 51(4), 1479-1497.

Malloy, C., T. Moskowitz, and A. Vissing-Jorgensen (2009): "Long-Run Stockholder Consumption Risk and Asset Returns," Journal of Finance, forthcoming.

Marcet, A., And R. Marimon (1999): "Recursive Contracts," Working Paper Universitat Pompeu Fabra.

Mehra, And E. Prescott (1985): "The Equity Premium: A Puzzle.," Journal of Monetary Economics, 15(2), 145-161.

Parker, J. A., And A. Vissing-Jorgensen (2009): "Who Bears Aggregate Fluctuations and How?," NBER Working Paper No. 14665.

REIS, R. (2006): "Inattentive consumers," Journal of Monetary Economics, 53, 1761-1800.

Saito, M. (1996): "Limited Participation and Asset Prices," Working Paper University of British Columbia.

Schneider, M., J. C. Hatchondo, and P. Krusell (2005): “A Quantitative Model of Competitive Asset Pricing Under Private Information," Working Paper Stanford University.

Sharpe, W. (1964): "Capital Asset Prices: A Theory of Market Equilibrium under Conditions of Risk," Journal of Finance, 19, 425-444.

Storesletten, K., C. Telmer, And A. Yaron (2004): "Cyclical Dynamics of Idiosyncratic Labor Market Risk," The Journal of Political Economy.

(2007): "Asset Pricing with Idiosyncratic Risk and Overlapping Generations," Review of Economic Dynamics, 10(4), 519-548. 